\title{
Improving teacher learning: variation in conceptions of Learning Study
}

\author{
Guy Durden \\ Department of Curriculum, Pedagogy and Assessment, UCL - Institute of Education, \\ London, UK
}

\begin{abstract}
Purpose: To identify teachers' conceptions of Learning Study in order to provide the basis for an application of phenomenography/variation theory to the improvement of teachers' learning about Learning Study.

Design: A phenomenographic study based on semi-structured interviews with 18 Beginner Teachers of Business and Economics in England taking part in a Learning Study during their initial teacher education.

Findings: The study identified five conceptions of Learning Study and five associated critical aspects. Results raise questions about the relationship between the process and instructional design elements of Learning Study.

Originality/Value: The study offers a framework for exploring differences in the quality of Learning Studies and the relationship between teacher conceptions of Learning Study and the degree of conceptual change in students in a Learning Study. It also enables facilitator/researchers to design and manage interventions to develop teacher understanding of Learning Study that are consistent with the principles of phenomenography/variation theory.
\end{abstract}

\section{Keywords}

Learning Study, phenomenography, conceptions, teacher development, Beginner Teachers

Department of Curriculum, Pedagogy and Assessment

UCL - Institute of Education

20 Bedford Way

London

WC1H 0AL

E-mail: g.durden@ucl.ac.uk

Telephone: +44 (0)7808 197452 


\section{Introduction}

Phenomenography/Variation Theory (PVT) proposes that people learn by experiencing variation in critical aspects of conceptions of a phenomenon. In a Learning Study, both teacher learning and student learning have been explained in terms of PVT (e.g. Wong \& Lo, 2008; Cheung \& Wong, 2014). However, accounts of Learning Study that focus on teacher learning (e.g. Pang \& Ling, 2012) highlight differences between the way in which students and teachers are exposed to variation. Students' experience variation that is tightly structured around a single phenomenon, the design of which has been the main purpose of the Learning Study. Teachers experience variation that is more loosely structured around a number of different phenomena and that occurs as a by-product of the focus on student learning. These differences could be interpreted as acting as constraints on teacher learning if the principles of PVT applied to student learning in a Learning Study are strictly applied to teacher learning.

In order to begin to address this difficulty, this study applies PVT to the phenomenon of Learning Study with the aim of identifying critical differences between conceptions of Learning Study. This is the first step in exposing teachers to more carefully structured variation in critical aspects which would help them develop a better understanding of Learning Study and thus make it more successful. In addition, identifying qualitative differences between teachers' understanding of Learning Study could allow the success of different Learning Studies to be compared in a manner akin to previous studies in the field (e.g. Pang \& Marton, 2003; 2005).

This study presents evidence of the conceptions of Learning Study of 18 Beginner Teachers (BTs) at two English universities in 2013/14. BTs were studying for teacher accreditation on a Post Graduate Certificate in Education in Business Studies and Economics. The Learning Study BTs undertook was closely modelled on that conducted by Pang and Marton (2003). The study begins by taking a more detailed look at teacher learning in a Learning Study from a PVT perspective, before describing the design of the study, results and discussing implications.

\section{Teacher learning in Learning Study}

A Learning Study involves a forensic examination of evidence of students' conceptions of a phenomenon and the identification of critical aspects of those conceptions. PVT proposes that more sophisticated conceptions of a phenomenon are acquired through managed variation of these critical aspects. In a Learning Study, the aim is to vary aspects of conceptions one at a time, whilst everything else is held constant, and then vary those aspects simultaneously to allow learners to develop a more sophisticated conception. In PVT, variation is a necessary but not a sufficient condition for this, since not all differences between conceptions are critical. In other words, according to PVT, variation in non-critical aspects of conceptions is unlikely to trigger conceptual change.

As a result of the above, in a Learning Study lesson, students' experience variation that is: i) tightly focused on a single phenomenon (or object of learning) and, ii) is very carefully 
sequenced. In contrast, teachers in a Learning Study are very likely to experience variation in aspects of a number of different phenomena. These include other teachers' ways of dealing with an object of learning, students' ways of understanding a topic and variation as a guiding principle for pedagogical design (Wong \& Lo, 2008). Since it is not a requirement of Learning Study that teachers' experience aspects of these phenomena in the same carefully managed way as students in a Learning Study, a number of consequences are likely to follow. Firstly, teachers will be exposed to variation in a large number of aspects of different phenomena. Secondly, given the complexity of the collaborative process in Learning Study, teachers are likely to be exposed to these aspects simultaneously or at best in very quick succession. Thirdly, these aspects will be a mixture of critical and non-critical aspects both in relation to any given phenomenon and in relation to a number of different phenomena.

This situation places a heavy demand on teachers. They need to distinguish aspects that are critical and aspects that are non-critical in relation to one phenomenon, as well as aspects that relate to one phenomenon and aspects that relate to another. The challenge in this task is increased if teachers are working with phenomena with which they are relatively unfamiliar (such as Learning Study). In addition, in order to make sense of simultaneous (or near simultaneous) variation in a large number of different aspects, teachers will need the capacity to independently manage the way they experience them. This means holding other aspects constant whilst only allowing themselves exposure to one aspect at a time. In a Learning Study lesson, this is something that teachers do for students, in order that students can focus on experiencing variation rather than managing the process.

Despite these challenges, there is evidence that teachers in a Learning Study do learn (e.g. Holmqvist, 2011; Tan \& Nashon, 2013). Teachers are used to managing highly complex classroom situations and so may be able to address the issues above, particularly if they have the support of a facilitator/researcher (as is usually the case in Learning Study).

However, previous studies provide evidence that is consistent with the idea that the way in which teachers' experience variation in Learning Study could restrict some teachers' learning. For example, Davies and Dunnill (2008) note significant qualitative shifts in the understanding and practice of some BTs taking part in Learning Study but relatively minor changes for others. This is a result confirmed by Durden (2016). In another example, Lo et al. (2005) claim that some of the teachers in their 3 year Learning Study project exhibited 'remarkable professional growth' (p.57), whilst 'relatively few' teachers recognised the benefits of identifying patterns of variation (p.62).

It is possible that differences in the learning between teachers in a Learning Study could be a result of other factors, for example, the experience of the teachers involved, their attitudes and beliefs and the way in which they work in a group. However, it is difficult to find detailed accounts of the way in which the critical aspects of Learning Study have been introduced to teachers in order to discount the importance of this. The following quotations give an indication of approaches taken:

'In the first stage, the framework of learning study and theory of variation were taught and discussed thoroughly in one three-hour lecture each week for six weeks. The theory of "OL" (Objects of Learning) and the theoretical groundings to understanding some of the necessary 
conditions for learning were also examined in the lecture' (Yee Lai $\mathcal{E}$ Wah Priscilla Lo-Fu, 2013, p.80).

'In the first learning study cycle, the teachers only got a brief introduction on the variation theory together with some articles to read ...... the researcher played an important role to introduce the concepts of the variation theory during the meetings' (Holmqvist, 2011, p.4).

'For the learning study group, variation theory was also introduced as a resource for designing the learning environment. First of all, the researcher presented some of the basic theoretical constructs of the theory of variation (as detailed in earlier section) in a less technical way. For instance, when explaining why discernment is a function of variation, examples of colour, sex and height were used, which were conceived to be easier for the teachers to comprehend. Furthermore, the researcher tried to exemplify how the variation theory could be applied to economics education, by making use of examples drawn from the teaching of the notion of price elasticity and tax incidence at Secondary 4 level' (Pang $\mathcal{E}$ Marton, 2005, p.168).

These descriptions of researcher interventions stand in contrast to descriptions of the meticulous way in which PVT is applied to students' learning in a Learning Study. For example, the first two quotations emphasise quite traditional approaches to teaching without reference to any underlying pedagogic principles, including PVT. On one reading, the third quotation may be at odds with the idea that learning occurs through the experience of difference against a background of sameness (Pang \& Marton, 2013). It could be taken to imply that teachers can learn by experiencing sameness (i.e. why discernment is 'a function of variation') against a background of difference (i.e. the particular example of variation).

These quotations suggest that descriptions of the critical aspects in teachers' conceptions of Learning Study might be useful to facilitator/researchers in conducting and evaluating Learning Studies. First, facilitator/researchers would be aware of the difference between critical and non-critical aspects. Second, they could use this knowledge to structure induction to Learning Study and guide teachers more effectively in any interactions that may occur during the process. Third, facilitator/researchers could understand more clearly the difference between teachers' initial conceptions of Learning Study and their target conceptions of Learning Study (reducing this difference is likely to increase teachers' ability to distinguish between critical and non-critical aspects of different phenomena). Finally, knowledge of critical aspects could be useful for the teachers involved in a Learning Study, since they could form a map to navigate through the complex Learning Study process.

\section{Method}

This study presents evidence of differences in the understanding of Learning Study of BTs completing 9 month Post Graduate Certificate of Education courses in two Universities in England in 2013/14. In line with standard approaches to phenomenographic research, the aim was to capture as wide a range of variation in BTs' conceptions as possible (Åkerlind, 2012). To this end, three criteria were used as indicators of diversity amongst BTs: i) 
undergraduate degree subject, ii) undergraduate degree classification and, iii) teaching ability (as assessed by University course leaders). BTs at the two Universities involved demonstrated a wide variation in terms of these three indicators. Each University course was structured differently, further increasing increased the chances of capturing the full range of conceptions.

BTs were asked to undertake a Learning Study on the phenomenon of price about a quarter of the way through their course. Price was chosen because of its prominence in previous PVT research. There were nine BTs in each University who were randomly divided into three groups of three. Each of the six groups prepared a lesson for a class of school students aged between 14 and 19 in two secondary schools (three classes in each school). For four of the groups, there was an opportunity to reteach the lesson to a different class in the same school. Two experienced teacher educator/researchers acted as facilitators throughout the Learning Study and then conducted the subsequent analysis.

The Learning Study closely followed the stages set out by Pang and Marton $(2003,2005)$ except that, in order to speed the process and to fit in with the course requirements at both Universities, the teacher educator/researchers: i) selected the object of learning and, ii) collected data on school students' conceptions. First, Learning Study was introduced to the BTs in two two hour briefing sessions, one on phenomenography and one on variation theory and the Learning Study process. In line with previous accounts, these sessions were in a standard lecture format and were not designed according to the principles of PVT.

Next, over three half days (about fifteen hours in total), BTs developed descriptions of conceptions of price. They drew on the responses from the school students in the intervention groups to a price problem set by one of the researchers $(n=118)$. BTs then planned lessons based around variation in what they perceived to be the critical aspects associated with these conceptions of price. They completed substantial additional preparation outside of the formal sessions.

Lessons were taught within a week of the final preparation sessions. One BT taught each lesson whilst the others gathered evidence of student learning through observation and the collection of student work. A few days after each Learning Study the teacher educator/researchers organised a post test, then worked alongside the BTs over half a day (about 5 hours) to analyse the extent to which students' understanding of price had become more sophisticated. This involved a comparison between pre and post tests as well as consideration of other evidence gathered during the lesson. BTs then discussed how they could improve the lesson in the future before redrafting them. They were encouraged to reteach their lessons during the rest of the University course.

About a month from the end of their course, all eighteen BTs were interviewed to gather evidence of their conceptions of Learning Study. These semi-structured interviews were between 35 and 55 minutes long and consisted of open ended questions to elicit BTs' understanding of Learning Study and situated questions to elicit concrete examples (Åkerlind, 2012). One important line of questioning was to ask BTs to explain the difference between the Learning Study lesson they had taught and their routine lessons and then illustrate these with examples. All interviews were transcribed and three were randomly chosen and reserved to check validity. 
To ensure that the meaning in the transcripts was captured as fully as possible, they were analysed iteratively 'from different perspectives at different times' (Åkerlind, 2012, p.122). Two teacher educator/researchers were involved in order to increase the chances of generating a wider range of perspectives (Trigwell, 2000). In this initial phase, each teacher educator/researcher worked independently over four weeks, repeatedly reading the transcripts and drafting and redrafting descriptions of conceptions based upon interpretation and reinterpretation of differences and similarities between BTs' responses. During this process, illustrative extracts were used, but their meaning was continually interpreted within the context of the whole transcript. This was done to gain the benefits of both a 'contextualised within the transcript' approach to extracts (e.g. Prosser, 1994) and a 'de-contextualised from the transcript' approach to extracts (e.g. Bowden, 2005). Repeated visits to the data along with a balance between a focus on extracts and a focus on context helped ensure that an awareness of the difference between the words spoken by BTs and their underlying meaning was maintained. This also helped minimise the risk of imposing any pre-conceived descriptions of conceptions (Ashworth \& Lucas, 2000).

In the final phase, the teacher educators/researchers worked together over eight weeks on the drafting and redrafting process, exchanging versions and reviewing and revising each other's work. Since an assumption of PVT is that different conceptions of a phenomena are structurally related, about half way through this time, the focus shifted from developing descriptions of conceptions to also describing the structure of conceptions. This process did not preclude revision of the descriptions of conceptions that were being developed (Åkerlind, 2012). In weeks six and seven, the scale of redrafting began to reduce and a stable set of logically related descriptions of conceptions emerged.

At the end of the process, the reliability of the descriptions of conceptions and their structure was checked by analysing the three reserved transcripts. Each was considered by the each of the teacher educator/researchers working independently, but they did not reveal any additional meanings or structural considerations. In order to help ensure that the claims in this study are defensible and valid, this account of method addresses each of the ten 'verification strategies' set out by Cope (2005) in relation to phenomenographic research.

\section{Results}

Six critical aspects of BTs' conceptions of Learning Study were identified along with five conceptions. The critical aspects are set out in order of increasing sophistication in Rows A - E in Table 1.0. Conceptions are set out in Columns $1-5$ in Table 1.0 and are also in order of increasing sophistication. When a critical aspect is highlighted in a conception, this is denoted by a shaded cell in Table 1.0. For example, Conception 1 (where BTs have a conception of Learning Study as a process for improving lessons) highlights BTs' experience in working with others and in reviewing and re-teaching lessons. In the following section, each conception is illustrated with quotations from BTs. 
Table 1.0 - Beginner Teachers' conceptions of Learning Study

\begin{tabular}{|c|c|c|c|c|c|c|c|}
\hline & \multicolumn{5}{|c|}{ BTs' conceptions of Learning Study } \\
\hline & & & 1 & 2 & 3 & 4 & 5 \\
\hline & & & $\begin{array}{l}\text { Improving } \\
\text { lessons by } \\
\text { following a } \\
\text { process }\end{array}$ & $\begin{array}{l}\text { Facilitating } \\
\text { students } \\
\text { taking } \\
\text { responsibility } \\
\text { for their } \\
\text { learning } \\
\end{array}$ & $\begin{array}{l}\text { Clarifying } \\
\text { the object of } \\
\text { learning for } \\
\text { the teacher }\end{array}$ & $\begin{array}{l}\text { Clarifying } \\
\text { different levels } \\
\text { of students' } \\
\text { understanding }\end{array}$ & $\begin{array}{l}\text { Transforming } \\
\text { students' } \\
\text { understanding } \\
\text { through } \\
\text { conceptual } \\
\text { change } \\
\end{array}$ \\
\hline \multirow{5}{*}{ 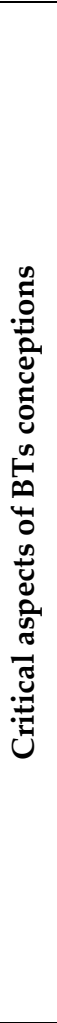 } & $\mathbf{A}$ & $\begin{array}{l}\text { Working with } \\
\text { others and } \\
\text { reviewing and } \\
\text { re-teaching } \\
\text { lessons }\end{array}$ & & & & & \\
\hline & B & $\begin{array}{l}\text { Focusing on } \\
\text { student activity } \\
\text { in lessons }\end{array}$ & & & & & \\
\hline & C & $\begin{array}{l}\text { Delimiting the } \\
\text { object of } \\
\text { learning from } \\
\text { its context }\end{array}$ & & & & & \\
\hline & $\mathbf{D}$ & $\begin{array}{l}\text { Determining } \\
\text { teaching } \\
\text { objectives by } \\
\text { reference to } \\
\text { levels of } \\
\text { student } \\
\text { understanding }\end{array}$ & & & & & \\
\hline & $\mathbf{E}$ & $\begin{array}{l}\text { Varying } \\
\text { features critical } \\
\text { to each level of } \\
\text { student } \\
\text { understanding }\end{array}$ & & & & & \\
\hline
\end{tabular}

\subsection{Conception 1: Experiencing Learning Study as a process for improving lessons}

Some BTs experienced Learning Study as a process for improving lessons. There were two distinct critical aspects of this conception: i) working with others and, ii) reviewing and reteaching. As neither of these two aspects seems to be logically more sophisticated than the other they are included in the same row (A) in Table 1.0. Quotation 1 is from a BT who found collaboration 'really beneficial' as a result of the pooling of ideas and the subsequent synergies. Quotation 2 emphasises the 'significant improvements' brought about by both the sharing of ideas and the cycle of refinement in Learning Study. 


\begin{abstract}
Quotation 1
I think that is really beneficial (working collaboratively) because you are not going at it with your own blinkers on then. Very often if you are in a lesson you go with it. If you are working in a group other people are bringing ideas forward and then you can all work together to try and produce the best lesson rather than just going with what your ideas are. Your ideas aren't necessarily right and if you can do it another way or if people have got experience of how it might work better, then it is great to pull all that together.

Quotation 2

we taught the lesson to begin with and we didn't teach it very well to be honest. We assumed too much from the students and the task was a little unfocused... we sat down and reviewed the lesson, made our changes, changed the resources, added new bits in, took bits away and taught it again to a new group. There was a significant improvement because we each contributed our perspective of the lesson. From where I was stood when I was speaking about me, my mind was on other things apart from necessarily me whereas other people were seeing the mistakes that I had made. So being able to sit down ........ and change things and make suggestions to each other and agree as a group where things went wrong it made a big difference to the way the second lesson was delivered.
\end{abstract}

There were some BTs who experienced connections between the theory of PVT and the process of Learning Study, seeing them as an integrated whole. For example, in Quotation 3 , the lesson is evaluated collaboratively in terms of Variation Theory and the 'high level of thinking' that was the aim of the lesson. However, there were other BTs who emphasised the distinction between theory and process. In Quotation 4 these are described as 'two different elements'. In a similar way, the BT in Quotation 5 explicitly distinguishes between the collaborative aspects and the 'idea' of Learning Study.

Quotation 3

In terms of what we did we worked closely together to actually plan a lesson unit based on the Variation Theory. We delivered those lessons with someone observing the lesson and then critiqued it and decided on ways to improve it looking specifically at showing if students were making progress and if the Variation Theory was achieving the high level of thinking that we wanted or moving the kids to where we wanted them to be.

Quotation 4

In terms of the learning study I found it particularly useful to have critical friends in the room and I got so much out of the discussions afterwards. In terms of the Variation Theory the idea that there can be levels of sophistication in understanding has really helped me. I am not sure how far I understand it yet but it has really made me think about what I am doing; so two different elements.

\title{
Quotation 5
}

In terms of how the Learning Study works in groups that is obviously useful because you get to meet and rub shoulders with other practitioners and you get to learn bits and pieces from them. I guess that isn't directly connected to the idea of Learning Study. 


\subsection{Conception 2: Facilitating students taking responsibility for their own learning}

For some BTs, Learning Study was a way of empowering students by giving them more responsibility to work things out for themselves. Quotation 6 contrasts 'spoon feeding' with a Learning Study approach where pupils 'really investigate topics themselves' and actively 'come to their own conclusions' in order to 'improve their higher order thinking and skills'. The BT in Quotation 7 sees Learning Study as 'completely different' to her normal practice of 'delivering' lessons and 'checking' understanding and seems to relish the experience of trusting her students to be 'independent learners'. Both quotations suggest a move away from an approach to teaching based on transmitting facts and emphasise the critical aspect of student activity as the way to achieve this.

\section{Quotation 6}

I thought learning study for me was a way of getting pupils to really investigate topics themselves and to come to their own conclusions be it guided or unguided which would then allow them to have more ability to explain and analyse knowledge than if it was just being spoon fed to them. Then they would also evaluate it. It is to improve their higher order thinking and skills.

\section{Quotation 7}

The main difference is that the students did the learning and did the work $100 \%$ rather than me having to do it. Many times it feels like I have got to deliver it, I have got to check that they have understood it, I have got to confirm that they have understood it as well. Whereas today it was completely different, yes of course I prepared the lesson but then they take responsibility for learning it and getting the outcomes that I expected them to get. That is the primary difference. I thought the level of involvement was a lot greater than what I would usually see ........ it felt quite good and nice to see that they are independent learners and I can trust them with it. I don't need to be their mother all the time.

\subsection{Conception 3: Clarifying the object of learning}

Both of the next two quotations refer to Learning Study as a way of improving BTs' understanding of what they are teaching. Quotation 8 highlights the 'potential to understand so much more' about the subject as a result of taking part in Learning Study, whilst Quotation 9 points to the way in which Learning Study might reinvigorate teachers by making them think more about the 'core subject matter'. Quotation 9 refers to the 'core' subject matter and the 'subject itself' and is taken to be drawing a distinction between a phenomenon (the 'core') and its context ('the subject itself'). Quotation 10 offers a similar experience in the reference to students learning the 'actual message'. In the use of quite dramatic language, Quotations 8 and 9 give a sense of the significance of the clarification of the object of learning. For example, Quotation 8 uses the phrase 'I had never thought about (this) that much in my whole life' and Quotation 9 asks rhetorically 'Why on earth are they (students) doing this?'

\section{Quotation 8}

The other benefits I think are that it just makes you think about the other subject knowledge so much like the example we used when we got all the PGCE (Post Graduate Certificate of Education) groups together and you (the researcher) got us to try and plan a mini learning 
study on triangles. I had never thought about triangles that much in my whole life. If you transpose that over into business and economics I have got the potential to just understand so much more about my subject through doing these Learning Study type activities.

Quotation 9

I think it is too easy for teaching to become monotony, it is too easy to walk in in the morning and get by on an average lesson and it is too easy to fall into a good level of consistency that is successful but maybe isn't enjoyable enough for the teacher or the pupils. That is really what the purpose of teaching should be and it has become too focused on everyone must know this and not why they should know it. I think that Learning Study reinvigorates it because it really makes you think about the core subject matter rather than the subject itself. Why on earth are they doing this? What are they expected to know?

Quotation 10

Okay, well as a teacher I guess it (Learning Study) gives you clarity on what specific thing they should be learning and then as a learner the method in which you deliver that learning should relate back to it. If you gave them another opportunity to apply that knowledge in a different situation they should still be able to apply it because they should have learnt the actual message.

\subsection{Conception 3: Clarifying different levels of student understanding}

BTs with this conception highlighted their understanding of qualitative differences in students' understanding of the object of learning and how the Learning Study lesson was more tightly focused on these in comparison to routine teaching. The BT in Quotation 11, frequently refers to 'levels of sophistication' to describe qualitative differences between conceptions. They are seen as a way of improving teaching because they provide a way thinking (or 'framework' in the words of the BT) about how to cater for individual students' learning needs (or 'differentiating' in the words of the BT). In the last sentence, whilst acknowledging the challenges of Learning Study, this BT comments on the extent to which Learning Study has helped clarify their understanding of the object of learning demonstrating Conception 3 in Table 1.0. In Quotation 12, the BT draws a distinction between student 'activity' in lessons and 'purposeful' learning. This BT sees qualitative differences in conceptions as allowing teachers to focus more on 'the progression' of students' learning and go beyond the 'mechanics' of a lesson. Determining teaching objectives by reference to the sophistication of students' understanding is proposed as the critical aspect of this conception.

\section{Quotation 11 \\ .......you are trying to communicate and consider the different levels of sophistication that a learner could understand that idea by and trying to develop the sophistication of that understanding .... Also actually having a really clear framework for differentiation based on the sophistication of understanding isn't maybe something I would... I would like to say that I did it more but if I am being honest I would say in the worst aspect of my teaching that just doesn't seem to happen. The idea of differentiation is just giving them easier questions or just giving them a more straight forward case study but actually it is not linked}


to this idea of starting at a lower level of sophistication of understanding and progressing them through that system. So for me that is a big difference because, just to try and explain that a little fuller, the way I look at differentiating my lessons wouldn't be based on sophisticated levels of understanding it was based on giving them something easier to do.... I find it (Learning Study) extraordinarily difficult, a lot harder than I thought it was going to be. I don't think I have actually ever considered an idea in my subject as fully until I tried to think about different levels of sophistication.

\section{Quotation 12}

I still do this myself and I am absolutely certain that other teachers do, not just within my department but other teachers' full stop, but have an activity almost for activity sake. 'It is an activity so that is good isn't it?', rather than 'it is an activity, yes, but what are the students actually getting out of it and is that activity purposeful in terms of moving students forward in their learning?'. I think that maybe what learning study does is focus a little bit more attention on the progression and development of a student's learning as opposed to just the mechanics or the stuff of 'I am delivering the lesson'.

\subsection{Conception 4: Transforming student understanding through conceptual change}

The final category focuses on conceptual change. The critical aspect in this way of thinking is variation in the critical features that distinguish one conception from another.

Quotations 13 and 14 can be taken to be expressing this in basic terms. Quotation 13 explains how 'elements' are 'varied one at a time' in a 'progressive way', whilst Quotation 14 emphasises 'chipping away at little bits' in order that 'hopefully it all fits together at the end '. Quotation 14 explains conceptual change in terms of the difference between 'knowing' and 'understanding' a topic. Throughout Quotation 13 there is a sense of movement and change in students' understanding. This is perhaps most clearly evident in the distinction made between 'activity' and thinking about 'where students are going'.

\section{Quotation 13}

I think in terms of varying, in a controlled and progressive way, elements of an activity and trying to maintain the control over the activity and the way that you design the activity in terms of varying one element at a time and then gradually moving through.... There is actually a control mechanism i.e., the Variation Theory, which I am sure is controlling what and why things happen within a particular activity or a series of activities through the lesson. Again it has quite an impact on the design of the lesson but it also makes you think about where the students are going and why they are going from $X$ to $Y$ to $Z$ rather than 'okay I can do that, then they will do that, that's a great activity, the kids will enjoy it'.

\section{Quotation 14}

As opposed to skimming the surface of just learning the basics that they have acquired it is pushing pupils to go deeper within. They can then understand how it builds on itself and in relation to other things as well, maybe, so that they understand the topic rather than just knowing it. In a normal lesson you are delivering the theory and then doing something with it whereas this isn't delivering the theory in a whole it is just taking aspects and changing little bits to then fit it all together. Instead of being told 'this is what you need to know, now 
apply it to this to consolidate it', it is chipping away at little bits and then hopefully it all fits together at the end.

\section{Discussion}

The strength of Learning Study is that it is a collaborative, iterative process that integrates teaching, learning, theory and research. However, this makes it a complex phenomenon that is tricky to learn about. Whilst BTs in this study often described positive experiences of Learning Study in quite powerful terms, a few were also very clear on the challenges. Quotation 15 gives an indication of this.

Quotation 15

I think as soon as you say 'Learning Study' there is a stiffness that goes through everyone and people 'clam up' because you don't maybe fully understand what you need to do and you are trying to do these amazing things but you are not really sure what it is that you are trying to achieve. I think that instils a fear through everyone at the beginning and then it makes it difficult. Also even though you are in groups, not everyone in the group has the same understanding.

The conceptions identified in this study could help address the 'stiffness' noted above. They describe possible milestones in BT learning, suggest how that learning might be sequenced and highlight critical markers in developing understanding of Learning Study. Conception 1 focuses on Learning Study as a process for improving lessons, whilst Conceptions 2 - 5 focus on Learning Study as an approach to instructional design. Conception 2 describes an orientation to teaching and learning that underpins Conceptions 3 and 4 which relate to phenomenography and Conception 5 which relates to variation theory. The critical aspects in Table 1.0 give the opportunity to apply variation theory. For example, moving a BT from Conception 3 to Conception 4 would mean them experiencing a situation in which teaching objectives were not determined by reference to levels of student understanding and one in which they were, and then allowing them to experience a situation where there was simultaneous variation in critical aspects $A, B, C$ and D.

This sort of activity would be particularly appropriate before Learning Study, in the introductory sessions led by facilitator/researchers. The conceptions identified in Table 1.0 might also be useful between Learning Studies as a way of diagnosing teachers' conceptions of Learning Study and working out the focus (and structure) of further interventions. The results could also be applied in the work of facilitator/researchers during Learning Study. Facilitator/researchers in Learning Study follow an 'emergent curriculum' (Edwards, 1993) in a similar way to facilitator/researchers in Lesson Study (Lewis, 2016), and this brings significant challenges in planning in advance. However, the conceptions (and critical aspects) in Table 1.0 can act as a framework within which researchers/facilitators can begin to interpret interactions with the participants in a Learning Study. This might be particularly useful for new researchers/facilitators and can be of benefit even in a highly complex, nuanced situation. For example, it is possible to imagine a researcher/facilitator responding immediately to a participant teacher by highlighting variation based on Table 
1.0. Although such 'in flight' course corrections may place demands on individual researchers/facilitators, this in an experience with which teachers are very familiar. This suggests that wherever possible, the researchers/facilitators involved in a Learning Study have high level teaching skills or are supported in developing them.

This study identified a difference between Learning Study as a process for improving lessons (Conception 1) and Learning Study as an approach to instructional design based on PVT (Conceptions $2-5)$. In their descriptions of Learning Study, most BTs emphasised either one or the other, with only 3 BTs making any explicit link between the two. In explaining the benefits of collaboration, BTs tended to make general points, such as 'sharing ideas', without referring to PVT. By contrast, for some BTs the process elements of Learning Study were not at all prominent in their thinking. For example, the BT in Quotation 7 refers to the way in which 'I prepared the lesson' (line 4) when in fact the lesson was developed with three other BTs.

This raises a question about the relationship between the process and instructional design elements of Learning Study. On the one hand, in the present study, collaboration generated variation that could provide the raw material for the acquisition of more sophisticated conceptions of Learning Study, for example in terms of the different approaches adopted by BTs to the object of learning. On the other hand, in Table 1.0, there does not appear to be a necessary connection between Conceptions $2-5$ (which are logically nested within each other) and Conception 1 . Previous studies that have compared 'Lesson Study' with 'Learning Study' have not directly addressed this issue, as they control for the instructional design element rather than the process element (Pang \& Marton, 2003; 2005).

It may be useful to separate the process elements more clearly from the instructional design elements both in preparing teachers for Learning Study and during it. This is partly because collaboration is a particularly complex phenomenon with the potential to generate considerable emotional 'heat'. There is the possibility, for example, that for a BT confronted with too much variation, the challenges of collaboration might assume an overriding significance that could cloud their ability to discern the instructional design elements of Learning Study. Facilitators/researchers, not alive to this possibility, could get caught up in this too.

One possibility is that BTs are introduced to variation in ways of collaborating and reviewing/re-teaching prior to any discussion of instructional design. This could help reduce the amount of variation and allow facilitators/researcher to more easily target variation in particular aspects. However, it would require work to establish critical aspects of the process elements of Learning Study and would also add to the time costs of Learning Study.

Another more radical possibility is that Learning Study is undertaken by an individual teacher without any collaboration. This would be consistent with the results of this study which suggest that it might be possible to achieve a high conception of Learning Study without exposure to the process aspects. A single teacher conducting a Learning Study may not experience the same amount of variation as when working collaboratively. However, there would still be powerful opportunities for an individual to experience the contrast between past and present experience (Marton et al., 2004) and, in any case, a 
reduction in the amount of ad hoc variation may be beneficial. A single teacher Learning Study would also reduce the resource demands considerably, as well as potentially closing the gap between a one-off Learning Study lesson and a teacher's routine practice.

The trade-offs highlighted above merit further exploration and the results of this study offer a basis for this. For example, in a similar manner to the approach taken to student learning in some studies of Learning Study (e.g. Pang \& Marton, 2003, 2005), they would allow a comparison to be made between the teacher learning taking place in one Learning Study, conducted in a particular way, and that taking place in another, conducted in a different way. In addition, they would allow a comparison to be made between the student learning take place in a Learning Study and the teacher learning taking place in a Learning Study.

\section{Conclusion}

This study has identified five conceptions of Learning Study (and their critical aspects) that can underpin an approach to teacher learning in Learning Study based upon PVT. The findings contribute to facilitators/researchers' knowledge of the difference between critical and non-critical aspects of the phenomenon of Learning Study. This knowledge can be applied in the design of activities to introduce Learning Study to teachers, as well as being a useful guide during the more ad hoc interactions that may occur throughout the process. In proposing descriptions of qualitatively different conceptions of Learning Study, this study also offers a basis for conducting comparative research, exploring the effects of different approaches to Learning Study on teachers' understanding of Learning Study and vice versa.

The generalisability of the results in this study may be restricted by the context. The study was conducted in initial teacher education in England with BTs in a single subject area and with a relatively modest sample size. It may be that teachers in other contexts in other countries, with different levels of experience or where Learning Study is embedded in routine practice in different ways, may experience Learning Study differently. Further research is required to establish the significance of these factors. However, this study: i) offers an initial explanation of why some teachers learn more in a Learning Study than others, ii) suggests how it may be possible to help more teachers learn more about Learning Study and, iii) does both in terms that are consistent with the principles of PVT.

\section{References}

Åkerlind, G. S. (2012) 'Variation and commonality in phenomenographic research methods', Higher Education Research \& Development, 31(1), pp. 115-127. doi: 10.1080/07294360.2011.642845.

Ashworth, P. and Lucas, U. (2000) 'Achieving Empathy and Engagement: A practical approach to the design, conduct and reporting of phenomenographic research', Studies in 
Higher Education, 25(3), pp. 295-308. doi: 10.1080/713696153.

Bowden, J. (2005) 'Underpinnings of phenomenography: Theory and practice', in Bowden, J. and Green, P. (eds) Doing Developmental Phenomenography. Melbourne: RMIT Unviersity Press.

Cheng, E. C. K. (2014) 'Learning Study: nurturing the instructional design and teaching competency of pre-service teachers', Asia-Pacific Journal of Teacher Education, 42(1), pp. 5166. doi: 10.1080/1359866X.2013.869546.

Cope, C. (2005) 'Ensuring validity and reliability in phenomenographic research using the analytical framework of a structure of awareness', Qualitative Research Journal, 4(2), pp. 518.

Davies, P. and Dunnill, R. (2008) "'Learning Study" as a model of collaborative practice in initial teacher education', Journal of Education for Teaching, 34(1), pp. 3-16. doi:

10.1080/02607470701773408.

Durden, G. (2016) An investigation into beginner teachers' knowledge and learning study. Birmingham University.

Edwards, C. P., Gandini, L. and Forman, G. E. (1993) The hundred languages of children : the Reggio Emilia approach to early childhood education. Ablex Pub. Corp.

Holmqvist, M. (2011) 'Teachers' learning in a learning study', Instructional Science, 39(4), pp. 497-511. doi: 10.1007/s11251-010-9138-1.

Lewis, J. M. (2016) 'Learning to lead, leading to learn: How facilitators learn to lead lesson study', ZDM, 48(4), pp. 527-540. doi: 10.1007/s11858-015-0753-9.

Lo, M. L., Pong, W. Y. and Chik, P. M. P. (2005) For each and everyone : catering for individual differences through learning studies. Hong Kong University Press.

Marton, F. and Tsui, A. (2004) Classroom discourse and the space of learning. L. Erlbaum Associates.

Ming Cheung, W. and Yee Wong, W. (2014) ‘Does Lesson Study work?', International Journal for Lesson and Learning Studies, 3(2), pp. 137-149. doi: 10.1108/IJLLS-05-2013-0024.

Pang, M. F. and Ling, L. M. (2012) ‘Learning study: helping teachers to use theory, develop professionally, and produce new knowledge to be shared', Instructional Science. Springer, 40, pp. 589-606. doi: 10.2307/43574702.

Pang, M. F. and Marton, F. (2003) 'Beyond "lesson study": Comparing two ways of facilitating the grasp of some economic concepts', Instructional Science. Springer, 31, pp. 175-194. doi: 10.2307/41953614.

Pang, M. F. and Marton, F. (2005) ‘Learning Theory as Teaching Resource: Enhancing Students? Understanding of Economic Concepts', Instructional Science, 33(2), pp. 159-191. doi: 10.1007/s11251-005-2811-0.

Pang, M. F. and Marton, F. (2013) 'Interaction between the learners' initial grasp of the 
object of learning and the learning resource afforded', Instructional Science. Springer Netherlands, 41(6), pp. 1065-1082. doi: 10.1007/s11251-013-9272-7.

Prosser, M. (1994) 'Some experiences of using phenomenographic research methodology in the context of research in teaching and learning.', in Bowden, J. and Walsh, E. (eds) Phenomenographic research: Variation in methods. Melbourne: RMIT, pp. 31-43.

Tan, Y. S. M. and Nashon, S. M. (2013) 'Promoting Teacher Learning Through Learning Study Discourse: The Case of Science Teachers in Singapore', Journal of Science Teacher Education, 24(5), pp. 859-877. doi: 10.1007/s10972-013-9340-5.

Trigwell, K. (2000) 'A phenomenographic interview on phenomenography', in Bowden, J. and Walsh, E. (eds) Phenomenography. Melbourne: RMIT University Press, pp. 62-82.

Wong, C. Y. and Lo, M. L. (2008) 'The implementation of the project', in Lo, M. L. et al. (eds) Variation for the Improvement of Teaching and Learning Final Report, pp. 18-28.

Yee Lai, M. and Wah Priscilla Lo-Fu, Y. (2013) 'Incorporating learning study in a teacher education program in Hong Kong: a case study', International Journal for Lesson and Learning Studies, 2(1), pp. 72-89. doi: 10.1108/20468251311290141. 